1

\title{
The high performance of nanocrystalline CVD diamond coated hip joints in wear simulator test
}

\author{
M.M. Maru ${ }^{1}$, M. Amaral ${ }^{2,3}$, S.P. Rodrigues ${ }^{2}$, R. Santos ${ }^{1}$, C. P. Gouvea ${ }^{1}$, B.S. Archanjo ${ }^{1}$, R.M. \\ Trommer $^{1}$, F.J. Oliveira ${ }^{2}$, R.F. Silva ${ }^{2}$, C.A. Achete ${ }^{1}$ \\ ${ }^{I}$ Materials Metrology Division, INMETRO, 25250-020, Duque de Caxias - RJ, Brazil \\ ${ }^{2}$ CICECO, Dept. of Materials and Ceramic Engineering, University of Aveiro, 3810-193 Aveiro, \\ Portugal \\ ${ }^{3}$ I3N, Physics Department, University of Aveiro, 3810-193 Aveiro, Portugal
}

Corresponding author: mmmaru@inmetro.gov.br

\begin{abstract}
The superior biotribological performance of nanocrystalline diamond (NCD) coatings grown by chemical vapor deposition (CVD) method was already shown to demonstrate high wear resistance in ball on plate experiments under physiological liquid lubrication. However, tests with a close-toreal approach were missing and this constitutes the aim of the present work. Hip joint wear simulator tests were performed with cups and heads made of silicon nitride coated with NCD of $\sim 10$ $\mu \mathrm{m}$ in thickness. Five million testing cycles (Mc) were run, which represent nearly five years of hip joint implant activity in a patient. For the wear analysis, gravimetry, profilometry, scanning electron microscopy and Raman spectroscopy techniques were used. After $0.5 \mathrm{Mc}$ of wear test, truncation of the protruded regions of the NCD film happened as a result of a fine-scale abrasive wear mechanism, evolving to extensive plateau regions and highly polished surface condition $(\mathrm{Ra}<10$ $\mathrm{nm}$ ). Such surface modification took place without any catastrophic features as cracking, grain pullouts or delamination of the coatings. A steady state volumetric wear rate of $0.02 \mathrm{~mm}^{3} / \mathrm{Mc}$, equivalent to a linear wear of $0.27 \mu \mathrm{m} / \mathrm{Mc}$ favorably compares with the best performance reported in the literature for the fourth generation alumina ceramic $\left(0.05 \mathrm{~mm}^{3} / \mathrm{Mc}\right)$. Also, squeaking, quite common phenomenon in hard-on-hard systems, was absent in the present all-NCD system.
\end{abstract}

Keywords: nanocrystalline CVD diamond, wear simulation, hip joint, silicon nitride

\section{Introduction}

Nanocrystalline diamond (NCD) coatings grown by chemical vapour deposition (CVD) are characterized by having diamond grain sizes typically in the range of 3-100 nm, with a relatively large fraction of hydrogen and amorphous carbon phases at the grain boundaries [1,2]. Due to the very small grain size, the intrinsic surface roughness of NCD films deposited on ultra-polished quartz or silicon substrates varies between $8 \mathrm{~nm}$ and $15 \mathrm{~nm}$ (RMS roughness) [2]. These morphological and topographic characteristics, together with diamond's extreme hardness and chemical inertness, are key factors for the application of NCD coatings in tribology. In fact, several works on the tribological behaviour of NCD-on-NCD contacts have been demonstrated the excellence of this tribopair [3-7]. Following a short-time running-in period where the protruding nanodiamond asperities suffer from truncation and blunting, the NCD-on-NCD sliding system attains a steady-state friction regime with very low friction coefficients $(0.01-0.05)$, characteristic of highly polished passivated surfaces [4-7]. A very mild wear regime is in line with this friction response, with low wear coefficient values in the range of $10^{-9} \mathrm{~mm}^{3} \cdot \mathrm{N}^{-1} \cdot \mathrm{m}^{-1}$ for water lubricated contacts [5] and one order of magnitude higher for dry systems [4]. A self-polishing micro-scale abrasive wear mechanism controls the wear behaviour of the NCD-on-NCD tribosystems [7]. A decisive feature for the good behaviour of NCD coatings in tribology is the adhesion level rendered by the use of silicon nitride $\left(\mathrm{Si}_{3} \mathrm{~N}_{4}\right)$ ceramics as substrates [8] due to the low thermal expansion 
coefficient mismatch and grain-to-grain epitaxial relationship between this ceramic and the diamond crystals, assisting the interface strength [9]. Additionally, $\mathrm{Si}_{3} \mathrm{~N}_{4}$ materials provide not only superior mechanical properties as a structural ceramic but also excellent biocompatibility [10, 11]. High threshold loading values before coating delamination for dry systems (60 N; $3.53 \mathrm{GPa}$ ) [7] and for water lubricated ones (85 N; $3.96 \mathrm{GPa})$ [5] were reported for ball-on-plate sliding experiments with NCD coated silicon nitride ceramic samples.

Having in mind the former considerations about the adequacy of NCD for tribology, summed up with NCD's biocompatibility [12-15], a great potential is foreseen for the application in biotribological systems. Aiming at this focus, works were performed under the lubrication with physiological fluids. In particular, NCD-on-NCD tribopairs were tested in bovine serum media, anticipating the performance of articulating surfaces of a novel joint prosthesis. Steady state friction coefficient values of 0.10 were recorded [16], higher than the values found for ceramic-on-ceramic and ceramic-on-metal (0.002-0.07), but considerably lower than for metal-on-metal combinations used in bearings for artificial hip joints $(0.22-0.27)$ [17]. The main reason for the friction value of the cited NCD coating lies on its relatively high starting surface roughness (RMS of 200-400 nm) [16] when compared to 5-10 $\mathrm{nm}(\mathrm{Ra})$ for the ceramics [17]. However, the wear coefficient values measured for NCD self-mated pairs in ball-on-plate tests under physiological liquid lubrication are of the order of $\sim 10^{-9}-10^{-8} \mathrm{~mm}^{3} \cdot \mathrm{N}^{-1} \mathrm{~m}^{-1}$ (mild to very-mild wear regime), values that are equal or even better than the wear factors assessed in similar test conditions for metal-on-metal $\left(\sim 10^{-7} \mathrm{~mm}^{3} \cdot \mathrm{N}^{-1} \mathrm{~m}^{-}\right.$ $\left.{ }^{1}\right)$, UHMWPE-on-metal $\left(\sim 10^{-7} \mathrm{~mm}^{3} \cdot \mathrm{N}^{-1} \mathrm{~m}^{-1}\right)$ and ceramic-on-ceramic $\left(\sim 10^{-8} \mathrm{~mm}^{3} \cdot \mathrm{N}^{-1} \mathrm{~m}^{-1}\right)$ contacts [15].

Nowadays, there is a real concern in developing solutions for long-term performance of total hip replacement (THR) joints. Life expectancy is increasing and also is the number of young patients who present hip damage due to severe sport injuries or accidents. This is a great challenge for materials like NCD with superior biotribological behaviour. The present work discusses the results of 5 million cycles of test in a hip wear simulator apparatus of all-NCD coated $\mathrm{Si}_{3} \mathrm{~N}_{4}$ ceramic hip joints. $\mathrm{Si}_{3} \mathrm{~N}_{4}$ ceramic substrates are produced by conventional powder technology route followed by machining with diamond hard tools into femoral head and acetabular cup geometries. The NCD coatings were grown on the contacting regions of $\mathrm{Si}_{3} \mathrm{~N}_{4}$ components by the hot filament CVD process.

\section{Experimental}

Femoral heads and acetabular liners, both of $28 \mathrm{~mm}$ nominal diameter, made of silicon nitride $\left(\mathrm{Si}_{3} \mathrm{~N}_{4}\right)$ bulk material, were fabricated according to the powder technology process described elsewhere in detail [18]. In brief, silicon nitride powder (AMPERPRESS Grade P, H.C. Starck) were uniaxial pressed at $160 \mathrm{MPa}$ into cylindrical shape $(40 \mathrm{~mm}$ diameter and $33 \mathrm{~mm}$ height $)$ and further machined into adequate dimensions, assuming 1.225 of shrinking green-sintered constant. The compacts were pressureless sintered in a conventional graphite furnace at $1750^{\circ} \mathrm{C} / 3 \mathrm{~h}$ in a nitrogen atmosphere. Surface finishing was firstly done by diamond tool machining to adjust to final dimensions and then by manual polishing steps, using different grit sizes.

Concerning the geometrical data of the head and the acetabular liner, these were as shown in the Table 1. The measurements were done in a tridimensional Coordinate Measuring Machine (Mytutoyo Legex 9106 model), with a scanning ball probe of $4 \mathrm{~mm}$ diameter.

A NCD coating of about $10 \mu \mathrm{m}$ in thickness was grown on the $\mathrm{Si}_{3} \mathrm{~N}_{4}$ surface by the hot filament CVD method, under the following deposition conditions: current intensity of $66 \mathrm{~A} ; \mathrm{CH}_{4} / \mathrm{H}_{2}$ flow ratio of 0.02 ; total pressure of 25 mbar; filament temperature of $2250^{\circ} \mathrm{C}$; substrate temperature of $650^{\circ} \mathrm{C}$; gas flow of $100 \mathrm{ml} / \mathrm{min}$; deposition time of $12 \mathrm{~h}$. Prior to deposition, the $\mathrm{Si}_{3} \mathrm{~N}_{4}$ ceramic 
surface was abraded for $1 \mathrm{~h}$ in ultrasonic bath with $6 \mathrm{~nm}$ sized diamond powder in ethanol suspension. The surface finishing of the specimens was performed manually by using soft cloths with diamond suspensions in a sequence of micrometrical particle sizes from $9 \mu \mathrm{m}$ to $3 \mu \mathrm{m}$ and finally colloidal silica.

A wear simulator machine (H52-6-1000 AMTI, Fig. 1), which mimics the biomechanics of the human hip joint through a hydraulically powered mechanical system, was used for the wear tests. Three simultaneous angular motions and an axial load were applied to the testing artificial joints as for those described in the ISO 14242-1 standard [19]. The angular motions - internal/external rotation (IR/OR), flexion/extension $(\mathrm{F} / \mathrm{E})$ and abduction/adduction (AB/AD) - run in a synchronized and cyclic fashion, at $1 \mathrm{~Hz}$ oscillation frequency. The angular length values were: $2^{\circ} \mathrm{IR}, 10^{\circ} \mathrm{OR}, 25^{\circ} \mathrm{F}, 18^{\circ} \mathrm{E}, 4^{\circ} \mathrm{AB}$ and $7^{\circ} \mathrm{AD}$. The axial load followed a physiological pattern with a maximum of $3,000 \mathrm{~N}$ and a minimum of $300 \mathrm{~N}$, applied through the central axis of the acetabular liner-head.

The acetabular liner was clamped by press fit into an appropriately fabricated metal shell, which was cemented with surgical cement into the respective holder. The femoral head was attached to the respective holder by a conical metal stem that goes press fitted through the tapered hole of the head. Fig. 2 shows the appearance of the acetabular liner and the head specimens mounted in the respective holders. For comparison purposes, a pair of bare $\mathrm{Si}_{3} \mathrm{~N}_{4}$ was also run together with the nanocrystalline diamond (NCD) coated pair. The black colour of the NCD coating on the right side is evident when compared to the greyish appearance of $\mathrm{Si}_{3} \mathrm{~N}_{4}$ bare specimens on the left. In the test, a plastic bag was used to keep each pair of specimens in closed circulating bath lubrication at 37 ${ }^{\circ} \mathrm{C}$. The used lubricant was sterilized alpha-calf serum with $30 \mathrm{~g} / \mathrm{L}$ of protein content (Vitrocell, batch number 007/12) mixed with $0.2 \%$ wt of sodium azide and $20 \mathrm{mM}$ of ethylenediaminetetraacetic acid (EDTA) for minimizing bacterial growth and calcium phosphate precipitation. The mounted pairs of specimens were placed in the simulator in anatomical position, with the liners on the top of the heads.

After every run of 0.5 million cycle $(1 / 2 \mathrm{Mc})$, the acetabular liners and the heads were removed from the simulator and cleaned for wear analysis purposes. The test then restarted with fresh lubricant, taking care to keep the same positioning of the tribopairs. This was made until completing $5 \mathrm{Mc}$, which represents 5 years in average of clinical operation of a hip joint implant in a patient under normal routine activities [20,21].

For the wear analysis, gravimetry, profilometry, microscopy and Raman spectroscopy techniques were used. The mass of the specimens was assessed with a high precision analytical balance (MSA225S-0CE-DI Sartorius, resolution of $0.01 \mathrm{mg}$ ). The surface topography was evaluated using a contacting profilometer (PGI830 Taylor Hobson) with a $2 \mu \mathrm{m}$ radius diamond tip stylus having a $90^{\circ}$ conical shape body. The measurements were performed in the $\mathrm{F} / \mathrm{E}$ and $\mathrm{AB} / \mathrm{AD}$ directions passing through the pole of the specimens, being 4 measurements of $10 \mathrm{~mm}$ length located orthogonally in four quadrants in the acetabular liners and 2 measurements of $12 \mathrm{~mm}$ length in the femoral heads. The average surface roughness parameter $(\mathrm{Ra})$ was calculated by first filtering the best-fitting circle from the measured profiles, using then a cut-off length of $0.08 \mathrm{~mm}$.

The microscopic features of the surfaces were assessed by scanning electron microscopy (SEM, FEI Magellan 400, FEI Quanta 200 and FEI Helios Nanolab 650) in the bare surface, without any conductive coating. The analyses of the NCD material were performed through Raman spectroscopy (Renishaw INVIA, $325 \mathrm{~nm}$ wavelength) in the pole region of the samples.

\section{Results and discussion}


Fig. 3a illustrates the homogeneity of the NCD coating grown on the bearing surface of the $\mathrm{Si}_{3} \mathrm{~N}_{4}$ femoral head component. The NCD morphology presents a uniform distribution of clusters of diamond grains (Fig. 3b), which reveal their nano-size feature at higher magnification (Fig. 3c). Such morphology was thoroughly described in early works $[5,8,22]$. In the set of micrographs of Fig. 4 the surface morphology after 1, 3 and $5 \mathrm{Mc}$ of wear testing can be compared to that of the pristine condition (Fig.4a). It is well evident that after wear the surfaces became smooth with some depressions in which unchanged NCD regions are apparent (Figs. 4b-4d). Truncation of the protruded regions corresponding to agglomerations of nanocrystalline grains was before described as the main factor for smoothing of the NCD coating in reciprocating sliding self-mated NCD systems [7, 16], named as fine-scale abrasive wear mechanism [7]. It is worth to note that, in the present hip joint wear simulator test there was absence of any delamination events in the coating, corroborating the adhesion quality of the NCD material to the $\mathrm{Si}_{3} \mathrm{~N}_{4}$ substrate, as found in ball-onplate reciprocating wear tests in water lubricated conditions [5].

The polished and unpolished regions of the worn surface after $5 \mathrm{Mc}$ of wear are shown in detail in Fig. 5. The polished area has no signs of cracking (Fig. 5a) revealing the high cohesive resistance of the NCD coating. This is a key property if one thinks of bearing surfaces made of hard materials. In the unpolished regions (Fig. 5b), still present after completing $5 \mathrm{Mc}$, the pristine grain morphology (Fig. 3c) is almost intact. These regions correspond to depressions that may act as lubricant reservoirs in the present hard-on-hard tribological system.

SEM images of the corresponding counterface, the NCD coated acetabular liner, are presented in Fig. 6. The pristine morphology in Fig. 6a is somewhat different from that of the femoral head, as the clusters of diamond nanocrystallites appear larger and with more round aspect. Such distinct morphologies are related to local conditions of temperature and atomic hydrogen etching of graphitic phases during the nucleation step of the CVD process [23] that should differ from convex to concave shapes. After $5 \mathrm{Mc}$ of wear testing, the clusters evolved to plateau regions (Fig. 6b) by a similar wear phenomenon to that described for the head component, i.e. polishing by fine-scale abrasion. Also, similarly to the head, the liner surface still presents some valley regions with unworn material (Fig. 6b). Ultimately, one can conclude that the surface modification takes place in both components without any catastrophic features as cracking, grain pullout or delamination of the coatings.

Despite the observed smoothening of the NCD surface, Raman spectroscopy analysis allowed concluding that no structural modifications of the diamond material took place during the wear process. This is manifest in the representative spectra taken from the pristine and the worn surfaces after $5 \mathrm{Mc}$ of both the femoral head (Fig.7a) and the acetabular liner components (Fig.7b). All spectra show the diamond peak $\left(\sim 1332 \mathrm{~cm}^{-1}\right)$ together with the $\mathrm{D}$ and $\mathrm{G}$ graphitic bands, respectively at $\sim 1370 \mathrm{~cm}^{-1}$ and $\sim 1570 \mathrm{~cm}^{-1}$, and the trans-polyacetylene (TPA) band $\left(\sim 1170 \mathrm{~cm}^{-1}\right)$ [24]. Graphite and TPA are well known phases that appear at the boundaries of the very small diamond crystallites [24].

\subsection{Surface roughness analyses}

A valuable set of information about the wear behaviour of the present NCD coated components is given by profilometry data. Representative surface roughness profiles of the head component obtained at the $0,0.5$ and $5 \mathrm{Mc}$ are presented in Fig. 8. In the pristine surface (Fig. 8a), the homogeneous feature of the morphology shown in Fig. 3a is reflected as a uniform topography. After $0.5 \mathrm{Mc}$, a significant change to a smooth fashion takes place (Fig. 8b), mainly localized at the centre of the profile within a length of approximately $3 \mathrm{~mm}$. This shows that the wear is more 
intense in the pole region of the spherical head. This wear feature remains up to the end of the test (Fig. 8c). The localized wear is the result of the concentration of the mechanical pressure axially applied in the test, at the top of the head.

Regarding the NCD coated acetabular liner counterface component, the profiles of the four quadrants of the pristine and the $0.5 \mathrm{Mc}$ and $5 \mathrm{Mc}$ tested surfaces are grouped in Fig. 9. Similarly to what was found for the head component, the topography of the pristine surface in Fig. 9a is very homogeneous, in line with the uniform clustered morphology shown in Fig. 6a. The profiles of the worn surface (Figs. 9b-i) show that the wear localizes in a short length region (3-4 mm) shifted from the centre of each profile. Such shift from the centre is a result of the asymmetrical angular motions of the liner in both $\mathrm{F} / \mathrm{E}$ and $\mathrm{AB} / \mathrm{AD}$ directions. Still from Fig. 9, it can be also noticed that the surface profiles remain almost similar from 0.5 to $5 \mathrm{Mc}$.

The Ra roughness values of the femoral head and acetabular liner surfaces obtained along the wear test are summarized in Fig. 10. A marked change in Ra is noticed from the pristine to the surface after $0.5 \mathrm{Mc}$ of test in both components. A difference in the Ra among the liner and the head is noted at the end of the test that is due to the existent difference in the pristine condition (Figs. 10ab). An observation must be pointed out related to the large standard deviation bars in Fig. 10b, which comes from the differences in the Ra values calculated from the roughness profiles of the four respective measured quadrants in the acetabular liner. Another distinction among the femoral head and the acetabular liner is the slight descending trend of $\mathrm{Ra}$ in the later (Fig. 10b) denoting that its final surface condition is still to be attained. The marked change in roughness from the pristine to $0.5 \mathrm{Mc}$ is even more evident if one considers the Ra values calculated in the localized worn regions (Figs. 10c-d). The resulting Ra values of about $0.003 \mu \mathrm{m}$ for the femoral head and $0.008 \mu \mathrm{m}$ for the acetabular liner denote an ultra-smooth surface finishing, adequate for hard bearing components. These values are a quantitative evaluation of the predominantly polished appearance of the head surface and the acetabular liner after $5 \mathrm{Mc}$, respectively shown in Figs. $5 \mathrm{~b}$ and $6 \mathrm{~b}$.

One of the most important remarks from the surface roughness analysis is that the running-in step of the NCD coated hip joint is completed during the first $0.5 \mathrm{Mc}$ of wear test. In the development of tribological systems, the minimization of the running-in step is a common concern due to the instability in the performance associated to high wear that can happen in this step. In this sense, in the case of the present NCD-on-NCD tribosystem one can suggest the minimization of the runningin step by performing a previous smoothening of the surfaces by a procedure that reproduces the $0.5 \mathrm{Mc}$ of run in the hip joint wear simulator.

\subsection{Wear rate evaluation}

The cumulative mass loss of the femoral head along the wear test is depicted in Fig. 11a. In the first $0.5 \mathrm{Mc}$ run, there was $0.69 \mathrm{mg}$ of mass loss, $70 \%$ of the total wear. This confirms that a net running-in step is completed in this time test, after which the wear becomes steady. By the wear rate behaviour in Fig. $11 \mathrm{~b}$ a steady-state wear rate of $(0.075 \pm 0.031) \mathrm{mg} / \mathrm{Mc}$ is attained. This value is equivalent to a volumetric wear rate of $(0.022 \pm 0.009) \mathrm{mm}^{3} / \mathrm{Mc}$, considering the density value of $3.41 \mathrm{~g} / \mathrm{cm}^{3}$ for the NCD material [25]. In the acetabular liner the corresponding volumetric wear rate value was estimated as $(0.14 \pm 0.03) \mathrm{mm}^{3} / \mathrm{Mc}$. The difference in the wear rate of the two components can be explained by the difference in the respective surface conditions after running-in. From 0.5 to $5 \mathrm{Mc}$, the Ra roughness values become less than $0.01 \mu \mathrm{m}$ in the femoral head (Fig. 10a) and within the range of $0.02-0.03 \mu \mathrm{m}$ in the case of the acetabular liner (Fig. 10b). This means that the surface elevations in the latter are still undergoing truncation. This phenomenon may be assisted by the intermittent tangential loading in the liner, contrarily to what happens on the femoral head surface where the pole region is permanently under contact. These observations let us to 
conclude that, for clinical application, previous polishing of the acetabular liner/head pair is imperative in order to minimize the running-in step observed in this work.

The application of the NCD coating on the $\mathrm{Si}_{3} \mathrm{~N}_{4}$ ceramic provides a remarkable improvement of the wear resistance if one compares the results among uncoated and coated conditions. For each one of the bare $\mathrm{Si}_{3} \mathrm{~N}_{4}$ components, a total mass loss around $50 \mathrm{mg}$ was measured for $5 \mathrm{Mc}$ of wear test. From the density of $3.22 \mathrm{~g} / \mathrm{cm}^{3}$ for $\mathrm{Si}_{3} \mathrm{~N}_{4}$, as measured by hydrostatic weighing, a volumetric wear rate of $3.1 \mathrm{~mm}^{3} / \mathrm{Mc}$ can thus be estimated for both the femoral head and the acetabular liner components. The marked difference in wear resistance between the tested uncoated and coated materials, of two orders of magnitude in the femoral head, is in line with results from pin-on-disc water lubricated tests, of $10^{-9} \mathrm{~mm}^{3} \cdot \mathrm{N}^{-1} \cdot \mathrm{m}^{-1}$ for NCD [5] and $10^{-7} \mathrm{~mm}^{3} \cdot \mathrm{N}^{-1} \cdot \mathrm{m}^{-1}$ for $\mathrm{Si}_{3} \mathrm{~N}_{4}$ self-mated contacts [26]. Tribochemical wear is the main wear mechanism of the $\mathrm{Si}_{3} \mathrm{~N}_{4}$ material in the presence of water [26] while diamond is chemically inert. From the author's knowledge, there is a single work with bare $\mathrm{Si}_{3} \mathrm{~N}_{4}$, components tested in a hip wear simulator machine that presented a volumetric loss of $0.2 \mathrm{~mm}^{3}$ after $1 \mathrm{Mc}$ of test [27]. This result was not reproduced in the present work. Probable explanations may be related the post-treatment of the $\mathrm{Si}_{3} \mathrm{~N}_{4}$ material by hot isostatic pressing or less severe wear test conditions, in the case of the cited work. It is clear that more studies dedicated to the wear behavior of $\mathrm{Si}_{3} \mathrm{~N}_{4}$ hip joints are necessary in order to elucidate this issue.

In the case of the NCD coated femoral head after running-in that resulted in a highly polished NCD surface, one can estimate an intrinsic linear wear rate. This is made by considering that the worn volume is a spherical cap with uniform thickness and a diameter of approximately $10 \mathrm{~mm}$ (the length of the worn region in Figs. 8b and 8c). From the volumetric wear rate of $0.022 \mathrm{~mm}^{3} / \mathrm{Mc}$, a predicted steady state linear wear of $0.27 \mu \mathrm{m} / \mathrm{Mc}$ is obtained. This is, up to the moment, the first value of the diamond-on-diamond wear rate of hip joints obtained from wear simulator tests. In the literature, only a computational estimation for PCD (polycrystalline diamond)-on-PCD contacts can be found, of $0.00292 \mathrm{~mm}^{3} / \mathrm{Mc}$ [28]. However, data used for such modelling were based on pin-ondisc tests from others [29]. An observation should be done when comparing NCD to PCD variety once NCD is a type of synthetic diamond with no metal, which is an advantage when compared to PCD that contains cobalt as a binder phase of the diamond grains. In the same cited work, the predicted volumetric wear rate of alumina-on-alumina couple is $0.17275 \mathrm{~mm}^{3} / \mathrm{Mc}$, equivalent to a linear wear rate of $1.317 \mu \mathrm{m} / \mathrm{Mc}$ [28]. For the fourth generation alumina ceramic (BIOLOX® delta) a value of $0.05 \mathrm{~mm}^{3} /$ million cycles obtained from hip wear simulator tests is reported [30].

Despite the wear tests performed on NCD, it is important to take into account that during the normal life of a patient, microseparation of the bearing centers of the femoral head and acetabular liner can occur. Microseparation causes edge loading, which changes the contact stress between the conforming spherical bearing surfaces and causes the presence of stripe wear in the ceramics [3133]. Stripe wear is originated from the intragranular [32] and intergranular [33, 34] fracture, with grain pullout [31]. The combination of hardness and fracture toughness (KIc) is here of high relevancy. NCD hardness (53.5 GPa [35]) is much superior to any grade of ceramic materials, namely of alumina based ceramics used in joint replacements (e.g. $19.4 \mathrm{GPa}$ for Biolox ${ }^{\circledR}$ forte and 22.5 GPa for Biolox ( ${ }^{\circ}$ delta [36]). On the other side, the KIc value of CVD diamond coatings with nanocrystalline morphology extends from 4 to $9 \mathrm{MPa} \mathrm{m}^{1 / 2}$ [37], a similar range to that of alumina based ceramics used in joint replacements (e.g. $4.3 \mathrm{MPa} \mathrm{m}^{1 / 2}$ for Biolox ${ }^{\circledR}$ forte and $8.5 \mathrm{MPa} \mathrm{m}{ }^{1 / 2}$ for Biolox ( $\AA^{\circledR}$ delta [36]. Consequently, better behavior of NCD comparing to alumina based ceramics it is expected when the possible effects of microseparation are considered.

In addition to the low wear of the NCD-on-NCD system, an important subject is the bioinertness of diamond. With this in mind, even if wear debris are released to the body, the problem of inflammations and aseptic loosening of conventional systems can be avoided when using all-NCD 
joints. Another important current concern in conventional hard-on-hard bearings is the squeaking phenomenon that results in audible noise during walking [38-41]. Explanations about the origin of such phenomenon are vast, including malpositioning, disruption of fluid film lubrication, stripe wear, and entrapment of third-body wear debris [38-41]. This phenomenon can be also observed in wear simulator experiments with ceramic components when third body particles are added to the contact region [41]. In the present NCD-on-NCD tested bearing specimens, no audible sound was noticed along all the test time.

\section{Conclusions}

From the performed hip wear simulator tests of novel all-NCD hip joints the following main results were attained:

- For highly polished surfaces one can reach a steady state volumetric wear rate of $0.02 \mathrm{~mm}^{3} / \mathrm{Mc}$, equivalent to a linear wear of $0.27 \mu \mathrm{m} / \mathrm{Mc}$. The best performance reported in the literature for the fourth generation alumina ceramic (BIOLOX® delta) is $0.05 \mathrm{~mm}^{3} / \mathrm{million}^{\circledR}$ cycles.

- Such surface condition was attained after $0.5 \mathrm{Mc}$ of wear test in the femoral head. Truncation of the protruded regions of the nanocrystalline grains happened as a result of fine-scale abrasive wear mechanism, evolving to extensive plateau regions.

- The surface modification takes place in both components without any catastrophic features as cracking, grain pullout or delamination of the coatings.

The wear rate of the acetabular liner component was higher than that of the femoral head because its initial high surface roughness is higher and also it suffers from intermittent tangential loading.

- The running-in step that occurred in the first $0.5 \mathrm{Mc}$ of wear test should be minimized by previous polishing of the surfaces.

- In addition to the high tribological performance, the well-known bioinertness of diamond should prevent inflammations and aseptic loosening even if wear debris are released to the body. Also, the squeaking phenomenon that commonly happens in hard-on-hard systems was not noticed in the all-NCD system.

All points considered, the wear performance of the NCD coated femoral head in the present work anticipates a competitive material compared to alumina-on-alumina, the best commercial ceramic material applied to hip joints.

\section{Acknowledgements}

This work was financed by FEDER funds through the Program Operational Factors of Competitiveness - COMPETE and Portuguese National funds through the FCT - Fundação para a Ciência e Tecnologia under projects FCOMP-01-0124-FEDER-015147 (PTDC/EMEPME/112910/2009). And CICECO-Aveiro Institute of Materials (Ref. FCT UID /CTM 150011/2013). R.F. Silva acknowledges the research grant from CNPq "Ciência sem Fronteiras" project. 402251/2012-1 "Nanostructured carbon allotropes". R.M. Trommer acknowledges the research grant from CNPq "Universal" project 471867/2013-6. Thanks are due to Dr. Erlon H Ferreira from Diffraction and Spectroscopy Laboratory (Lades) of Inmetro, for the Raman spectroscopy analyses, to Dimensional Metrology Laboratory (Lamed) for the CMM measurements, and to Eduardo Soares from DURIT - Metalurgia Portuguesa do Tungsténio, Lda, for the manufacturing of the ceramic parts.

\section{References}


[1] Williams OA. Nanocrystalline diamond. Diam Relat Mater 2011;20:621-40.

[2] Liu X, Klauser F, Memmel N, Bertel E, Pichler T, Knupfer M, Kromka A, Steinmüller-Nethl D. Spectroscopic studies of nanocrystalline diamond materials. Diam Relat Mater 2007;16:1463-70.

[3] Amaral M, Abreu CS, Fernandes AJS, Oliveira FJ, Gomes JR, Silva RF. Nanodiamond-based tribosystems. Surf Coat Techn 2010;204:1962-9.

[4] Abreu CS, Amaral M, Fernandes AJS, Oliveira FJ, Silva RF, Gomes JR. Friction and wear performance of HFCVD nanocrystalline diamond coated silicon nitride ceramics, Diam Relat Mater 2006;15:739-44.

[5] Abreu CS, Amaral M, Oliveira FJ, Gomes JR, Silva RF. HFCVD nanocrystalline diamond coatings for tribo-applications in the presence of water. Diam Relat Mater 2009;18:271-5.

[6] Mubarok F, Carrapichano JM, Almeida FA, Fernandes AJS, Silva RF. Enhanced sealing performance with CVD nanocrystalline diamond films in self-mated mechanical seals. Diam Relat Mater 2008;17:1132-6.

[7] Salgueiredo E, Abreu CS, Amaral M, Oliveira FJ, Gomes JR, Silva RF. Self-mated tribological systems based on multilayer micro/nanocrystalline CVD diamond coatings. Wear 2013;303:225-34.

[8] Almeida FA, Amaral M, Oliveira FJ, Fernandes AJS, Silva RF. Nano to micrometric HFCVD diamond - adhesion strength to Si3N4. Vacuum 2007;81:1443-47.

[9] Almeida FA, Oliveira FJ, Silva RF, Baptista DL, Peripolli SB, Achete CA. High resolution study of the strong diamond/silicon nitride interface. Appl Phys Lett 2011;98:171913

[10] Guedes e Silva CC, Higa OZ, Bressiani JC. Cytotoxic evaluation of silicon nitride-based ceramics. Mater Sci Eng C 2004;24:643-6.

[11] Taylor RM, Bernero JP, Patel AA, Brodke DS, Khandkar AC. Silicon nitride: a new material for spinal implants. J Bone Joint Surg Br 2010;92-B (SUPP I):133.

[12] Amaral M, Gomes PS, Dias AG, Lopes MA, Silva RF, Santos JD, Fernandes MH. Nanocrystalline diamond: in vitro biocompatibility assessment by MG63 and human bone marrow cells cultures. J Biomed Mater Res A 2008;87:91-99.

[13] Amaral M, Gomes PS, Lopes MA, Silva RF, Santos JD, Fernandes MH. Cytotoxicity evaluation of nanocrystalline diamond (NCD) coatings by fibroblast cell cultures. Acta Biomater 2009;5:755-63.

[14] Thalhammer A, Edgington RJ, Cingolani LA, Schoepfer R, Jackman RB. The use of nanodiamond monolayer coatings to promote the formation of functional neuronal networks. Biomaterials 2010;31:2097-104.

[15] Bendali A, Agne C, Meffert S, Forster V, Bongrain A, Arnault J-C, Sahel JA, Offenhausser A, Bergonzo P, Picaud S. Distinctive Glial and Neuronal Interfacing on Nanocrystalline Diamond. PLoS ONE 2014;9(3):e92562.

[16] Amaral M, Abreu CS, Oliveira FJ, Gomes JR, Silva RF. Tribological characterization of NCD in physiological fluids. Diam Relat Mater 2008;17:848-52.

[17] Jin ZM, Stone M, Ingham E, Fisher J. Biotribology. Curr Orthop 2006;20:32-40.

[18] Rodrigues SP, Paiva JM, De Francesco S, Amaral M, Oliveira FJ, Silva RF. Artifact level produced by different femoral head prostheses in CT imaging: diamond coated silicon nitride as a future biomedical application. J Mater Sci: Mater Med 2013;24:231-39.

[19] International Standard ISO 14242-1 (2012). Implants for surgery - Wear of total hip-joint prostheses - Part 1: Loading and displacement parameters for wear-testing machines and corresponding environmental conditions for test.

[20] Essner A, Sutton K, Wang A. Hip simulator wear comparison of metal-on-metal, ceramic-onceramic and crosslinked UHMWPE bearings. Wear 2005;259:992-5. 
[21] Saikko V, Ahlroos T, Calonius O, Keränen J. Wear simulation of total hip prostheses with polyethylene against $\mathrm{CoCr}$, alumina and diamond-like carbon. Biomaterials 2001;22:150714.

[22] Amaral M, Fernandes AJS, Vila M, Oliveira FJ, Silva RF. Growth rate improvements in the hot-filament CVD deposition of nanocrystalline diamond. Diam Relat Mater 2006;15:1822-27.

[23] Lee S-T, Linb Z, Jiang X. CVD diamond films: nucleation and growth. Mater Sci Eng 1999;25:123-54.

[24] Ferrari AC, Robertson J. Origin of the $1150 \mathrm{~cm}-1$ Raman mode in nanocrystalline diamond. Phys Rev B 2001;63:121405-1-121405-4.

[25] Shen ZH, Hess P, Huang J P, Lin YC, Chen KH, Chen LC, and Lin ST. Mechanical properties of nanocrystalline diamond films. J Appl Phys 2006;99:124302.

[26] Chen M, Kato K, Adachi K. Friction and wear of self-mated SiC and Si3N4 sliding in water. Wear 2001;250:246-55.

[27] Bal BS, Khandkar A, Lakshminarayanan R, Clarke I, Hoffman AA, Rahaman MN. Testing of Silicon nitride ceramic bearings for total hip arthroplasty. J Biomed Mater Res Part B: Appl Biomater 2008;87B:447-54.

[28] Uddin MS, Zhang LC. Predicting the wear of hard-on-hard hip joint prostheses. Wear 2013;301:192-200.

[29] Harding D, Blackburn D, Loesener G, Dixon R, Nguyen BK. Wear rate comparison between polycrystalline diamond, $\mathrm{CoCr}$, and UHMWPE in high wear environments. International Society for Advanced Spine Surgery (ISASS) Conference, 28-29 April, 2011, Nevada, USA.

[30] Al-Hajjar M, Leslie IJ, Tipper J, Williams S, Fisher J, Jennings LM. Effect of cup inclination angle during microseparation and rim loading on the wear of BIOLOXVR delta ceramicon-ceramic total hip replacement. J Biomed Mater Res B Appl Biomater 2010;95:263-8.

[31] Walter WL, Insley GM, Walter WK, Tuke MA. Edge Loading in Third generation alumina ceramic-on-ceramic bearings - Stripe wear. J Arthroplasty 2004; 19:402-13.

[32] Mak M, Jin Z, Fisher J, Stewart TD. Influence of acetabular cup rim design on the contact stress during edge loading in ceramic-on-ceramic hip prostheses. J Arthroplasty 2011; 26: $131-6$.

[33] Tipper JL, Hatton A, Nevelos JE, Ingham E, Doyle C, Streicher R, Nevelos AB, Fisher J. Alumina-alumina artificial hip joints. Part II: Characterisation of the wear debris from in vitro hip joint simulations. Biomaterials 2002; 23:3441-8.

[34] Zeng P, Rainforth WM, Inkson BJ, Stewart TD. Transmission electron microscopy analysis of worn alumina hip replacement prostheses. Acta Mater 2012; 60:2061-72.

[35] Wenzhuang L, Wei F, Han W, Jun X, Qunchao H, Min Z, Dun-Wen Z. Nano Hardness and Elastic Modulus of Nanocrystalline Diamond Coating. Integr Ferroelectr, 2014; 152:152-7.

[36] Pria PD. Evolution and new application of the alumina ceramics in joint replacement. Eur J Orthop Surg Traumatol. 2007; 17:253-6.

[37] Hess P. The mechanical properties of various chemical vapor deposition diamond structures compared to the ideal single crystal. J Appl Phys. 2012; 111:051101-1-15

[38] Gallo J, Goodman SB, Lostak J, Janout M. Advantages and disadvantages of ceramic on ceramic total hip arthroplasty: A review. Biomed Pap Med Fac Univ Palacky Olomouc Czech Repub 2012;156:204-12.

[39] Buttaro MA, Zanotti G, Comba FM, Piccaluga F. Squeaking in a Delta Ceramic-on-Ceramic Uncemented Total Hip Arthroplasty. J Arthrop 2012;6:1257-9.

[40] Stanat SJC, Capozzi JD. Squeaking in Third- and Fourth-Generation Ceramic-on-Ceramic Total Hip Arthroplasty. Meta-Analysis and Systematic Review. J Arthrop 2012;27:445-53. 
[41] Sariali E, Jin Z, Stewart T, Fisher J. Spectral Characterization of Squeaking in Ceramic-onCeramic Total Hip Arthroplasty: Comparison of In Vitro and In Vivo Values. J Orthop Res 2012:185-9. 


\section{List of figure captions}

FIGURE 1: Image of one of the wear stations of the multi station hip wear simulator machine.

FIGURE 2: General view of the femoral heads and acetabular cups made of bare silicon nitride (left side) and NCD coated silicon nitride (right side).

FIGURE 3: SEM images of the NCD coating grown on the bearing surface of the Si3N4 femoral head component, pristine condition. a) Overall morphology showing homogeneity of the coating; b) uniform distribution of clusters of the nanodiamond grains; c) grains at high magnification revealing their nano-size feature.

FIGURE 4: Comparative SEM images of the NCD surfaces before wear (a) and after 1Mc (b), 3Mc (c) and $5 \mathrm{Mc}(\mathrm{d})$.

FIGURE 5: SEM image of the NCD coated head surface (a) and detail of the less worn region at higher magnification (b).

FIGURE 6: SEM images of the NCD coated acetabular liner surface before wear (a) and after 5Mc (b).

FIGURE 7: Raman spectra of the NCD coated hip components, comparing the pristine condition to after $5 \mathrm{Mc}$ of wear test. a) Femoral head; b) acetabular liner.

FIGURE 8: Roughness profiles of the NCD coated femoral head obtained at the pole region. a) Pristine condition; b) after $0.5 \mathrm{Mc}$ of wear test; c) after $5 \mathrm{Mc}$ of wear test.

FIGURE 9: Roughness profiles of the NCD coated acetabular liner taken at the pole region in the 4 quadrants (0o, 90 o, 180 o. 270 o and 90 o). (a) Pristine condition; (b-e) after 0.5 Mc; (f-i) after 5 Mc.

FIGURE 10: Ra roughness values of the tested hip components. a) Femoral head in the $10 \mathrm{~mm}$ and c) $3 \mathrm{~mm}$ evaluation length; acetabular liner in the b) $10 \mathrm{~mm}$ and d) $3 \mathrm{~mm}$ evaluation length.

FIGURE 11: Results from the gravimetric measurements of the NCD femoral head along the 5 MC of wear test. a) Cumulative mass loss; b) wear rate.

\section{List of table captions}

Table 1: Geometrical data of the NCD coated silicon nitride ceramic head and acetabular liner obtained from CMM measurements. 


\section{FIGURES}

Figure 1: Image of one of the wear stations of the multi station hip wear simulator machine.

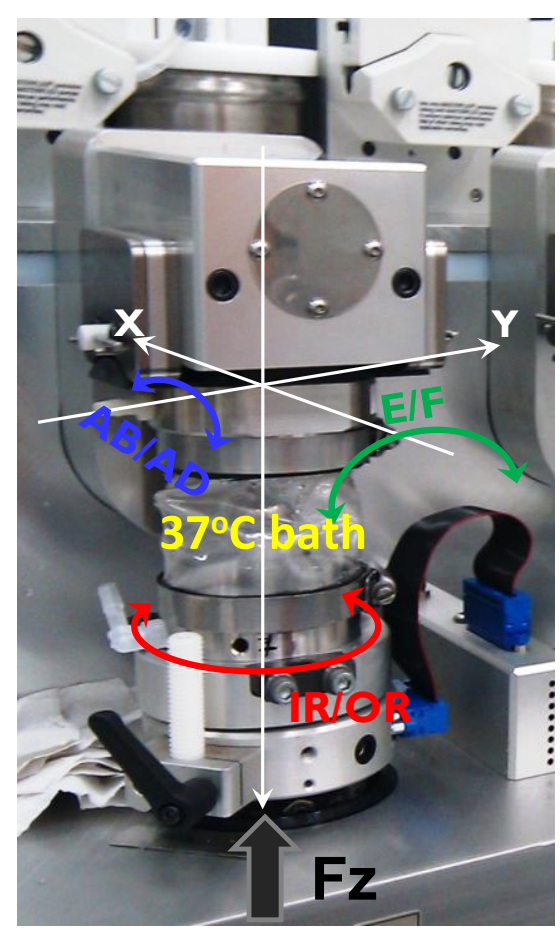


FIGURE 2: General view of the femoral heads and acetabular cups made of bare silicon nitride (left side) and NCD coated silicon nitride (right side).

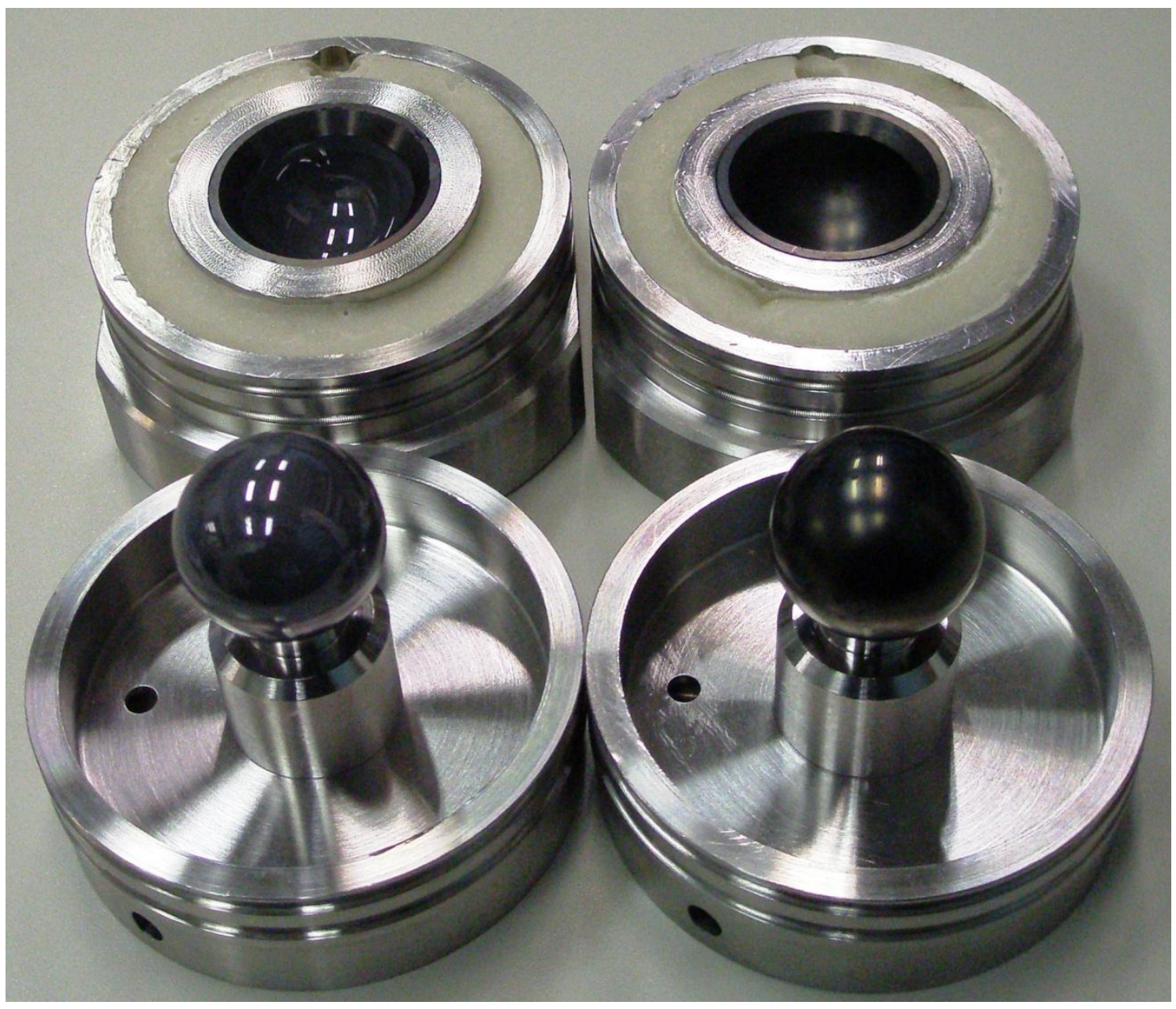


Figure 3: SEM images of the NCD coating grown on the bearing surface of the $\mathrm{Si}_{3} \mathrm{~N}_{4}$ femoral head component, pristine condition. a) Overall morphology showing homogeneity of the coating; b) uniform distribution of clusters of the nanodiamond grains; $c$ ) grains at high magnification revealing their nano-size feature.
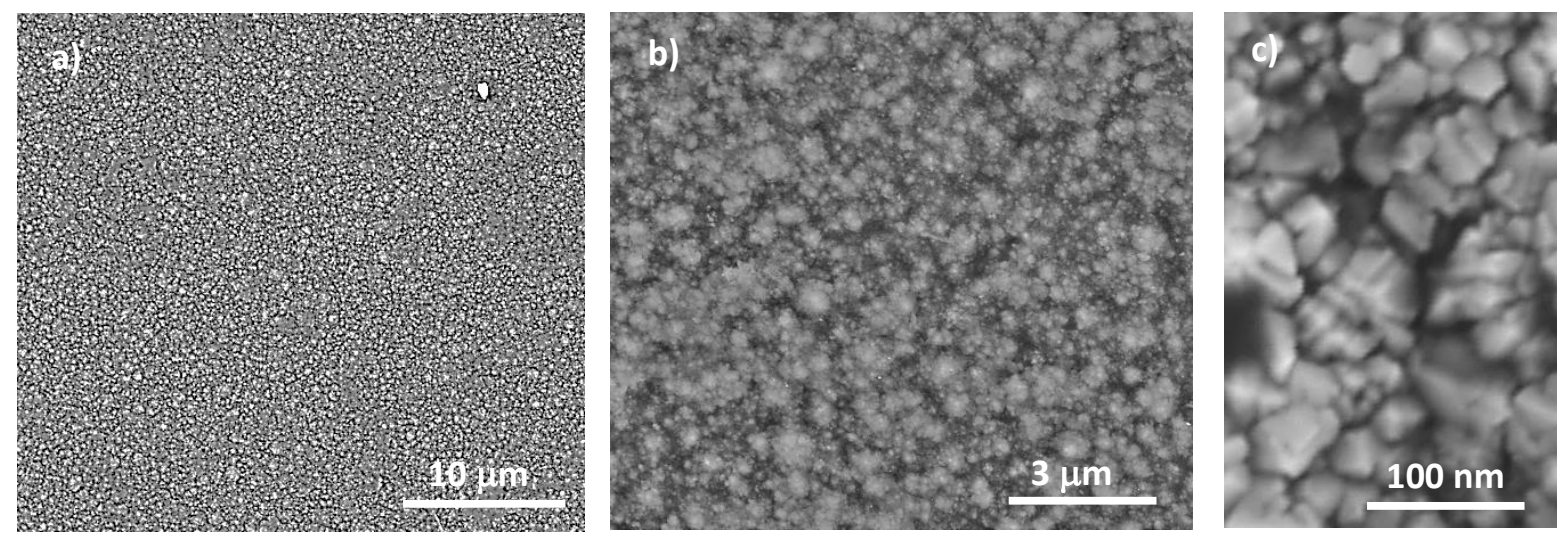
Figure 4

FIGURE 4: Comparative SEM images of the NCD surfaces before wear (a) and after $1 \mathrm{Mc}(\mathrm{b}), 3 \mathrm{Mc}(\mathrm{c})$ and $5 \mathrm{Mc}(\mathrm{d})$.
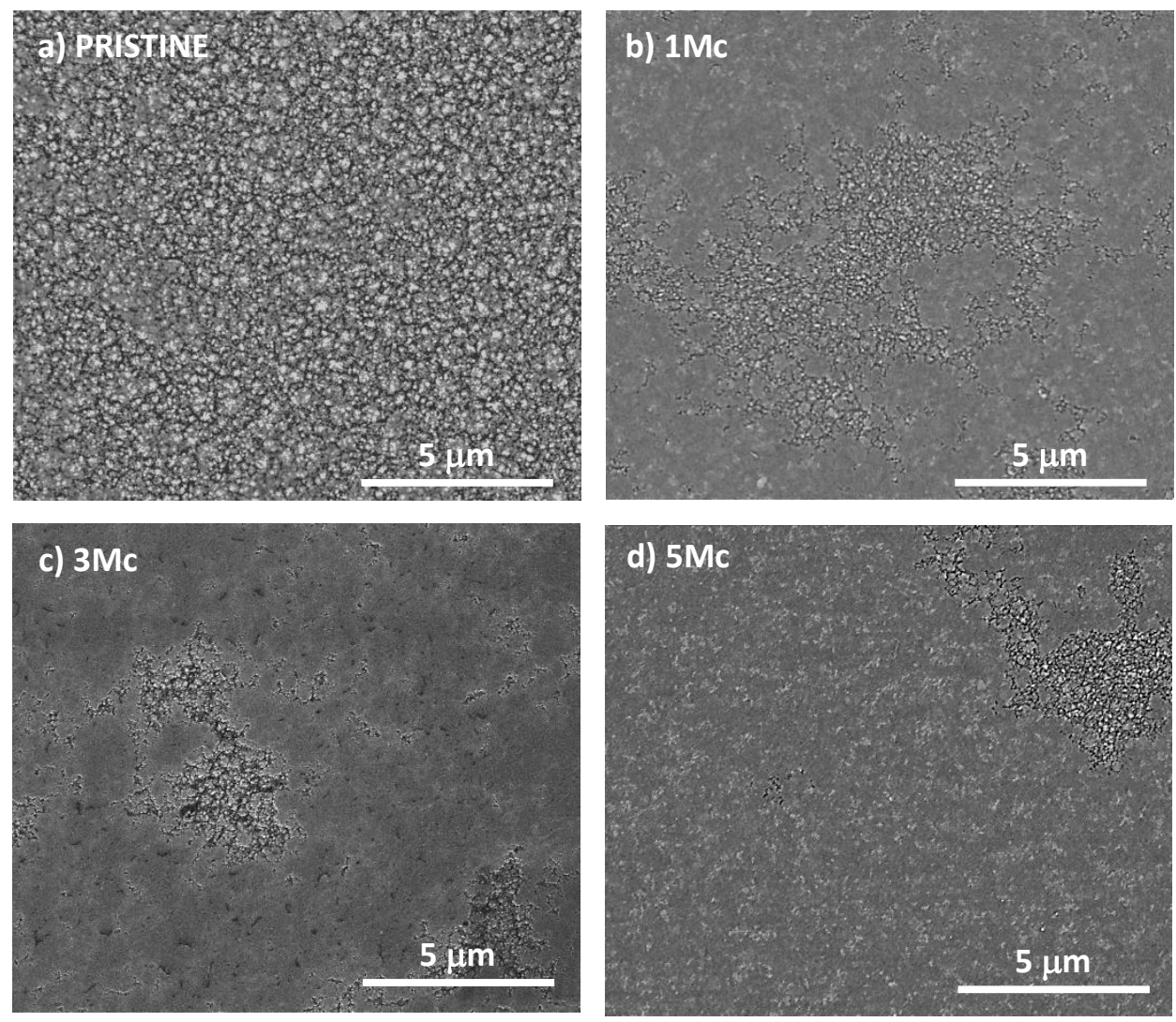
Figure 5

FIGURE 5: SEM image of the NCD coated head surface (a) and detail of the less worn region at higher magnification (b).
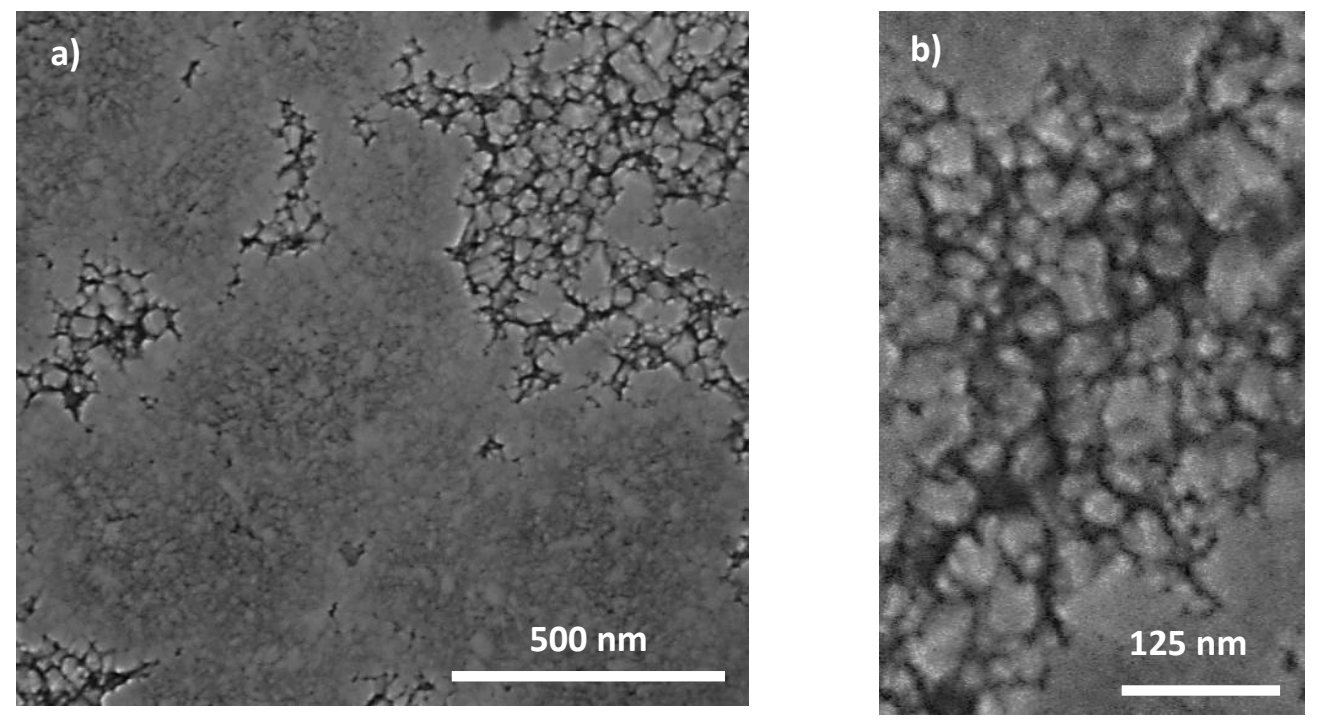
Figure 6

FIGURE 6: SEM images of the NCD coated acetabular liner surface before wear (a) and after $5 \mathrm{Mc}(\mathrm{b})$.
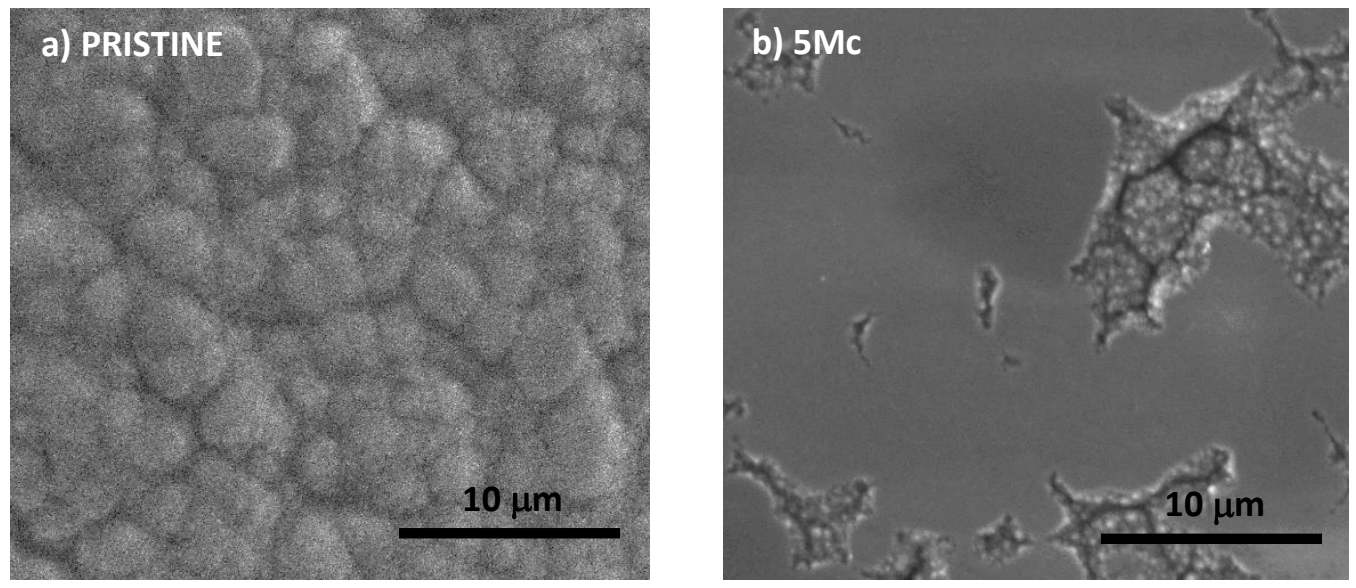
FIGURE 7: Raman spectra of the NCD coated hip components, comparing the pristine condition to after $5 \mathrm{Mc}$ of wear test. a) Femoral head; b) acetabular liner.

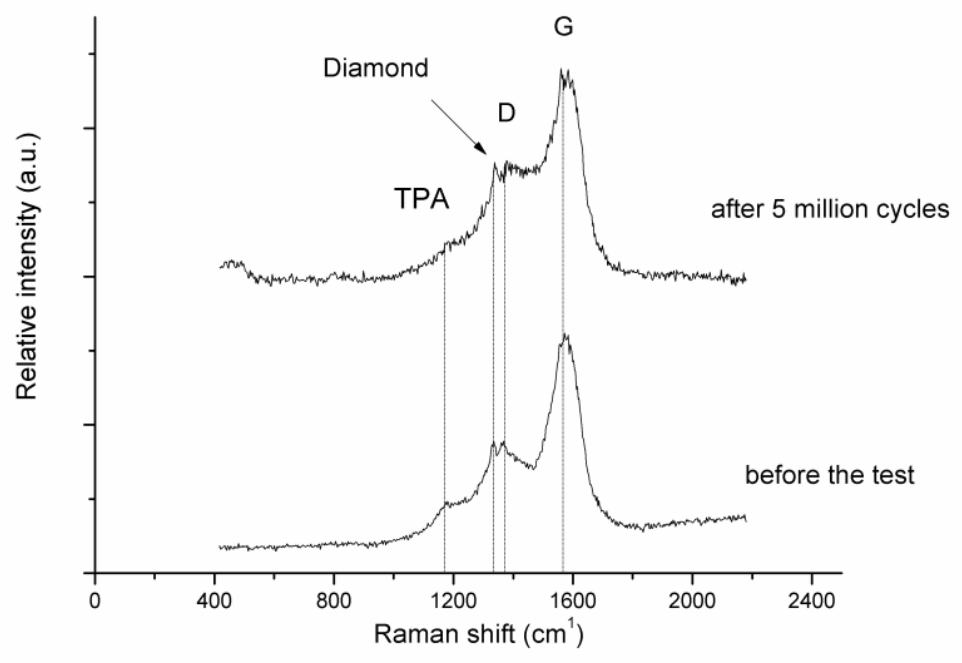

a) Femoral head

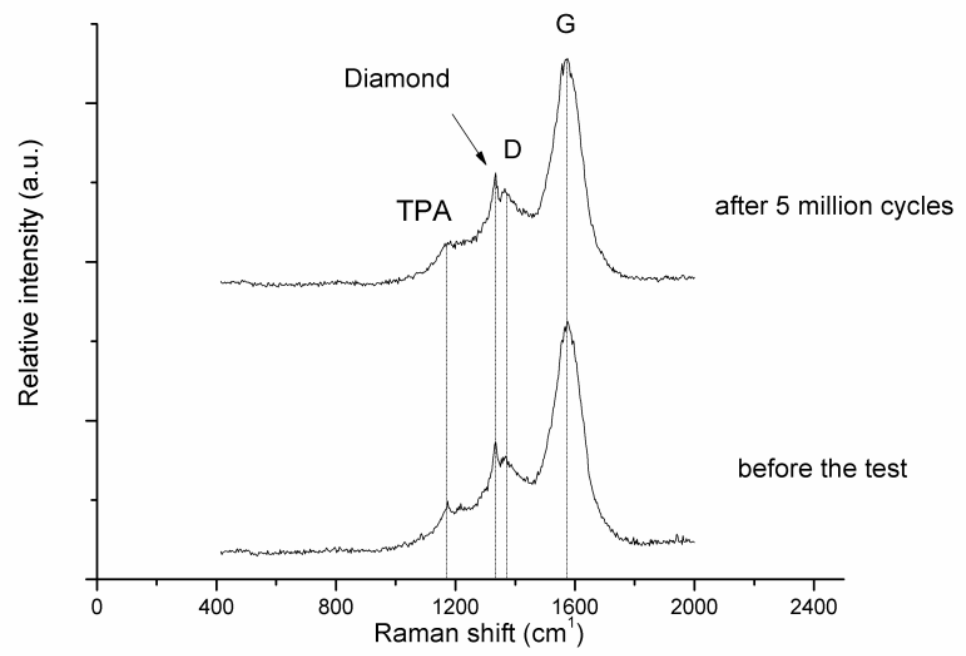

b) Acetabular liner 
FIGURE 8: Roughness profiles of the NCD coated femoral head obtained the pole region. a) Pristine condition; b) after $0.5 \mathrm{Mc}$ of wear test; c) after $5 \mathrm{Mc}$ of wear test.
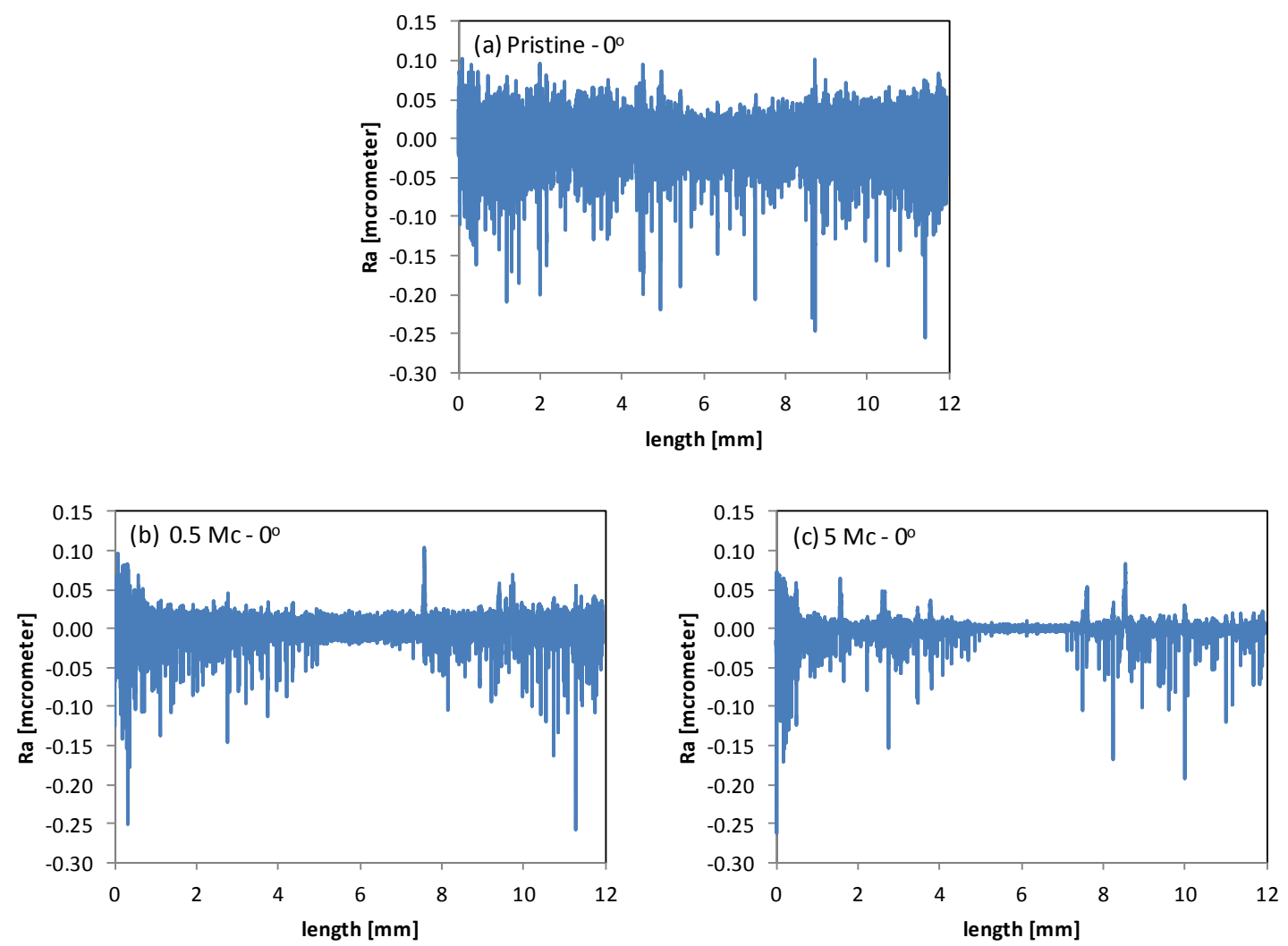
FIGURE 9: Roughness profiles of the NCD coated acetabular liner taken at the pole region in the 4 quadrants $\left(0^{\circ}, 90^{\circ}, 180^{\circ} .270^{\circ}\right.$ and $\left.90^{\circ}\right)$. (a) Pristine condition; (b-e) after $0.5 \mathrm{Mc}$; (f-i) after $5 \mathrm{Mc}$.
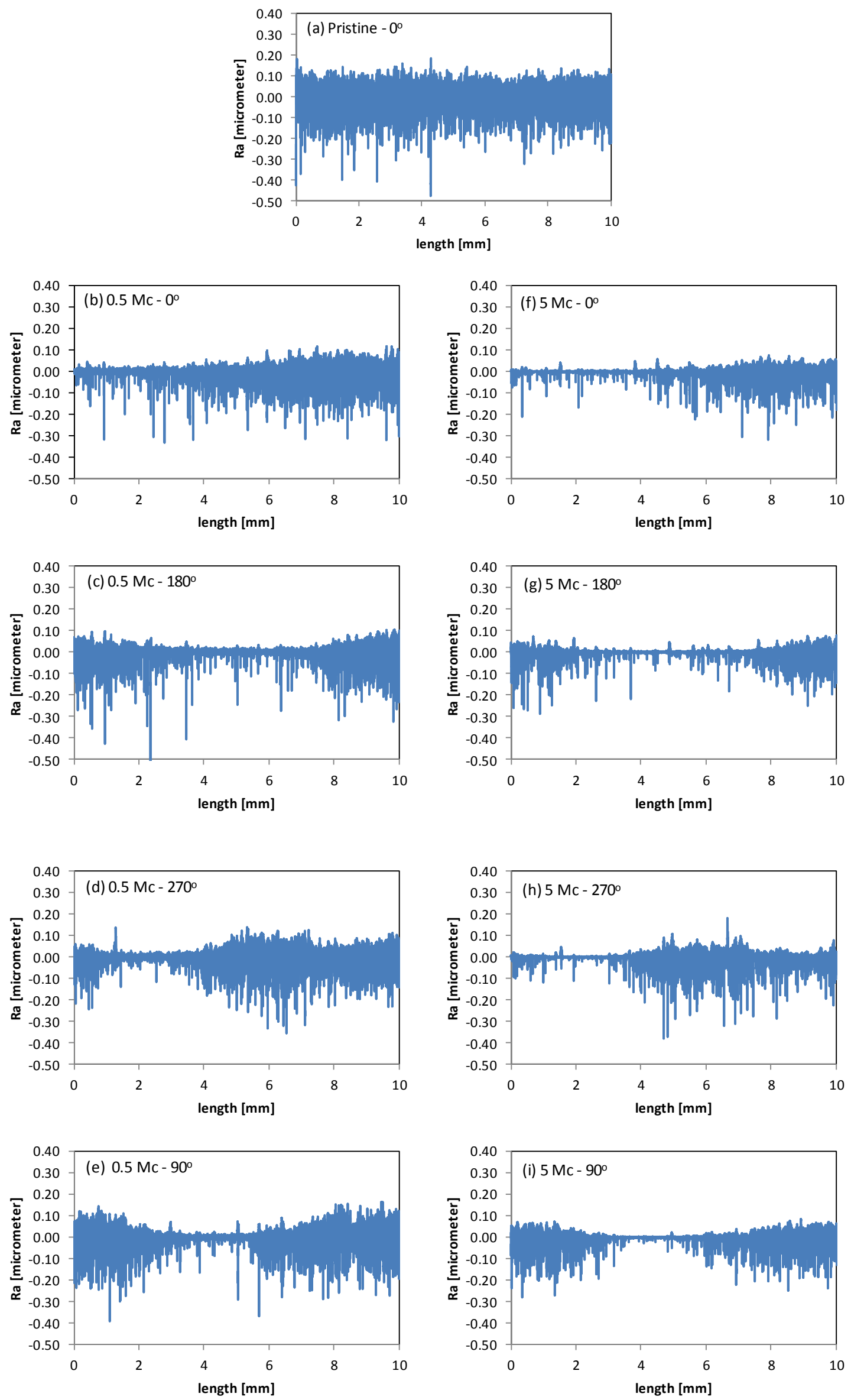
FIGURE 10: Ra roughness values of the tested hip components. a) Femoral head in the $10 \mathrm{~mm}$ and c) $3 \mathrm{~mm}$ evaluation length; acetabular liner in the b) $10 \mathrm{~mm}$ and d) $3 \mathrm{~mm}$ evaluation length.

a) Ra head $10 \mathrm{~mm}$ length

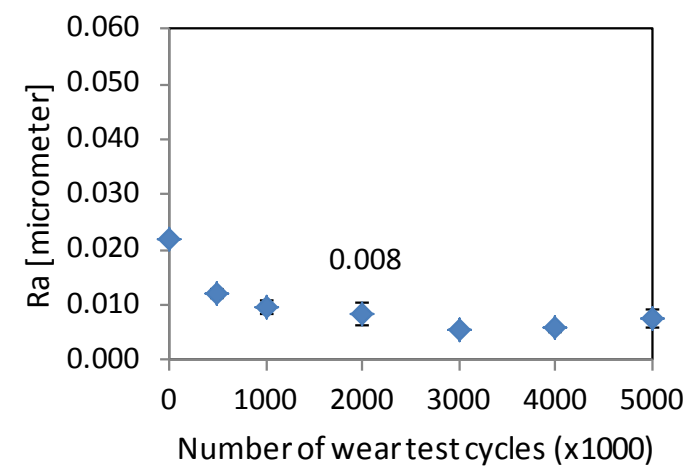

c) Ra head $3 \mathrm{~mm}$ worn length

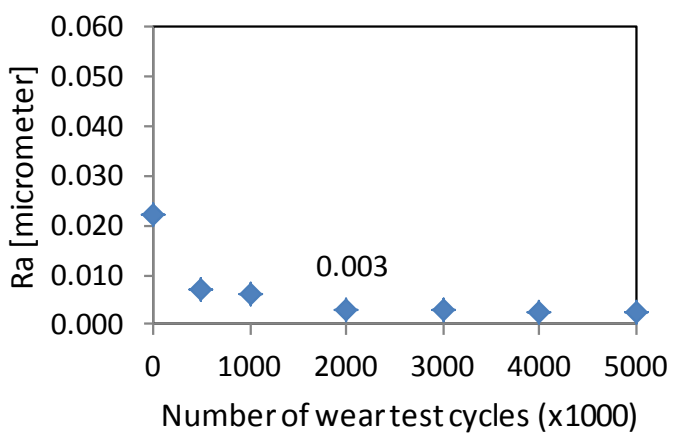

b) Ra liner $10 \mathrm{~mm}$ length

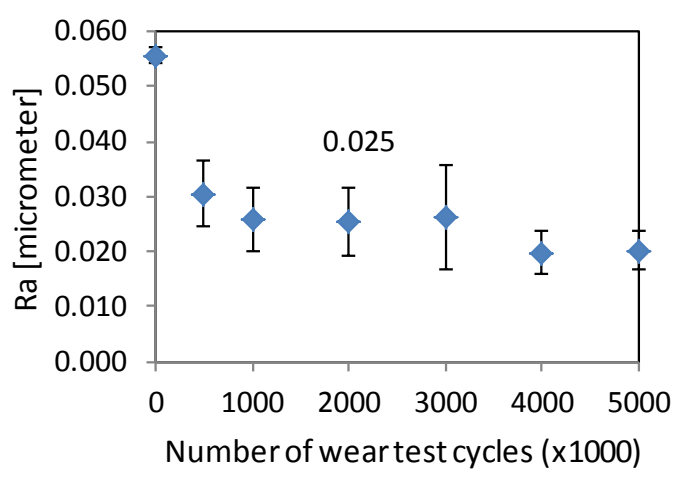

d) Ra liner $3 \mathrm{~mm}$ worn length

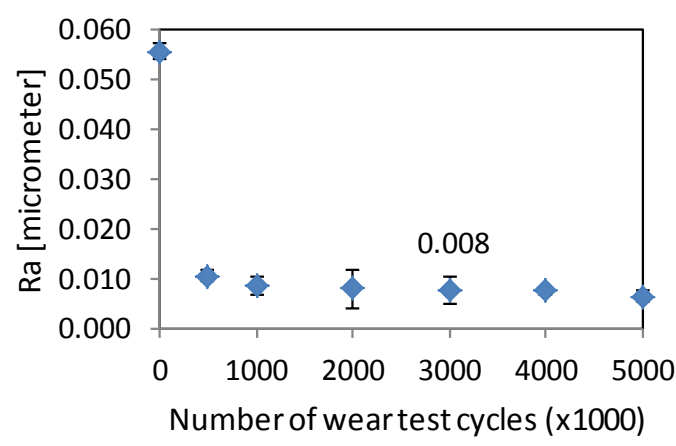


Figure 11: Results from the gravimetric measurements of the NCD femoral head along the 5 $\mathrm{MC}$ of wear test. a) Cumulative mass loss; b) wear rate.

a) head cumulative wear [mg]

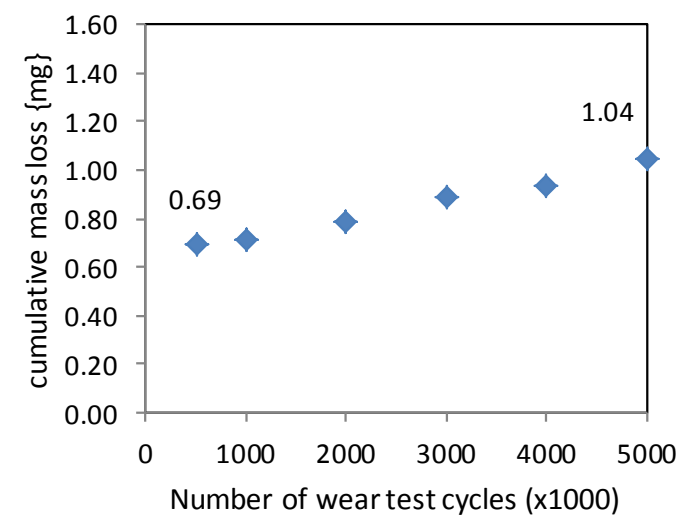

b) head wear rate $[\mathrm{mg} / \mathrm{Mc}]$

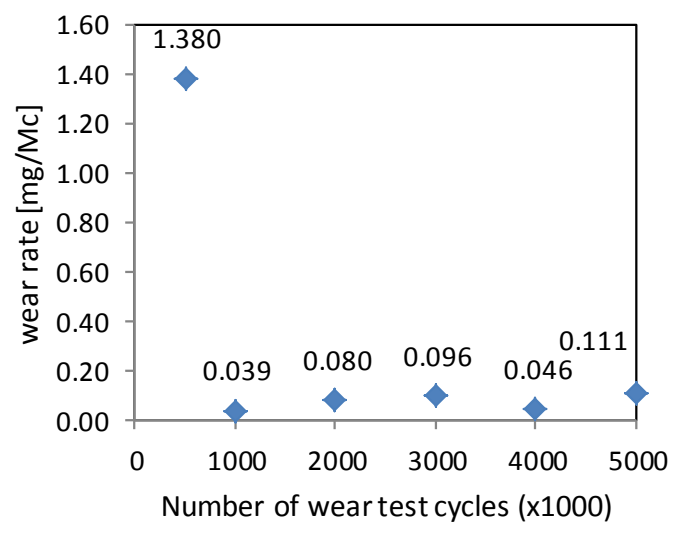


Table 1: Geometrical data of the NCD coated silicon nitride ceramic head and acetabular liner obtained from CMM measurements.

\begin{tabular}{|c|c|c|c|}
\hline Specimen & Diameter $[\mathrm{mm}]$ & $\begin{array}{c}\text { Radial clearance } \\
{[\mu \mathrm{m}]}\end{array}$ & $\begin{array}{c}\text { Sphericity deviation } \\
{[\mu \mathrm{m}]}\end{array}$ \\
\cline { 1 - 1 } Head & 27.88 & 78 & 3.4 \\
\hline Liner & 27.96 & 78.1 \\
\hline
\end{tabular}

